\title{
Límites del lenguaje cinematográfico en el cine experimental durante el tardofranquismo
}

\section{Limits of Film Language in the Experimental Cinema in Late-Francoism}

\author{
Luis Deltell Escolar y Juan García Crego
}

Universidad Complutense de Madrid 1deltell@ccinf.ucm.es / juangarc@ucm.es

Recibido: 21-08-2014

Aceptado: 16-01-2015

\section{Resumen}

Durante los últimos años de la dictadura franquista, en el denominado período del tardofranquismo, un grupo de creadores y cineastas experimentales abordaron una serie de proyectos en los cuales cuestionaron la escritura y el lenguaje cinematográficos. Paulino Viota, Pere Portabella e Isidoro Valcárcel Medina filmaron tres títulos que investigaron sobre el lenguaje cinematográfico y la importancia de la actuación clásica. Contactos (Paulino Viota, 1970), Vampir-Cuadecuc (Pere Portabella, 1970) y La celosía (Isidoro Valcárcel Medina, 1972) representan los tres modelos más radicales de esta búsqueda de los límites de la escritura cinematográfica.

Palabras clave: Cine experimental, Cine español, Isidoro Valcárcel Medina, Pere Portabella, Paulino Viota.

\section{Abstract}

In the last years of the Franco dictatorship, Late-Francoism, three filmmakers and artists filmed three experimental movies: Contactos (Paulino Viota, 1970), Vampir-Cuadecuc (Pere Portabella, 1970) y La celosía (Isidoro Valcárcel Medina, 1972). These movies explore what the meanings of the Cinema. Viota, Portabella y Valcárcel Medina attempted to find the limits of the Film Language. 
Keywords: Experimental Cinema, Spanish Cinema, Isidoro Valcárcel Medina, Pere Portabella, Paulino Viota.

\section{Introducción y antecedentes}

En 1970 se publicó en México El inocente, un libro del poeta español José Ángel Valente. Uno de los textos incluidos se titulaba «Sobre un tiempo presente» y comenzaba así: "Escribo desde un naufragio, / desde un signo o una sombra, / discontinuo vacío / que de pronto se llena de amenazante luz. Escribo sobre el tiempo presente, / sobre la necesidad de dar un orden testamentario a nuestros gestos"1. Ese tiempo presente, el final del franquismo, fue vivido por los artistas y creadores como un naufragio. El gobierno militar del general Franco parecía caduco y ya mortalmente herido, pero aún resistente. El poemario El inocente revelaba una lucha continua por "dar un orden" a esa tiempo presente. Un orden que no se correspondía en absoluto al modelo establecido por la dictadura.

Aunque el concepto tardofranquismo es muy discutido y rebatido 2 , para los historiadores y analistas resulta evidente que los últimos años del régimen fueron los más convulsos desde el final de la contienda fratricida. Tras la clausura en diciembre de 1965 del Concilio Vaticano II y el viraje social de la Iglesia Católica, el general Franco había perdido su último aliado ideológico. Había conseguido el apoyo militar y económico de los países del bloque occidental (en especial de los Estados Unidos), mas para lograr estos poderosos aliados había abandonado todos los rasgos inherentes y originarios.

La estructura del estado español se tambaleaba. Las voces críticas y los cineastas beligerantes surgían en todos los lugares. A pesar de la feroz represión o de los métodos coercitivos como la Junta de Clasificación y Censura, cada grieta en el andamiaje del régimen era utilizada para expresar las carencias de ese tiempo presente. Las discrepancias nacían incluso desde los despachos del los políticos afines. Así un ex Director General de Cinematografía, José María García Escudero, llegó a afirmar en esos años: "El cine español es como nuestro país: un cine subdesarrollado que ahora llama a las puertas del club de los desarrollados, sin que todavía tenga asegurado su ingreso en él"3.

La situación dentro de la industria cinematográfica no era mucho más favorable. Tras el fallido intento de un resurgimiento empresarial y de prestigio basado en el Nuevo Cine Español y, en menor medida, en la Escuela de Barcelona, el sector

\footnotetext{
1 Valente, J. Á. La voz de José Ángel Valente. Poesía en la Residencia, Madrid, Publicaciones de la Residencia de Estudiantes, 2001, pp. 24-25.

2 Tusell, J., Dictadura franquista y democracia: 1939-2004, Barcelona, Crítica, 2005.

3 García Escudero, J. M., Vamos a hablar de cine, Madrid, Biblioteca básica, Salvat, 1970, p. 145.
} 
fílmico se encontraba agotado. Como indica Emilio C. García Fernández es un período "perdido" de la industria 4 . Los directores más leales al franquismo (como Rafael Gil, Juan de Orduña o José Luis Sáenz de Heredia) habían sido arrinconados en las ayudas oficiales en el último lustro y su producción resultaba excesivamente ampulosa hasta para los propios censores que hacía años no les otorgaban ni las mejores calificaciones ni los premios estatales. Los jóvenes directores disidentes, ante el rechazo institucional y comercial, habían suavizado la radicalidad de sus discursos. La revolución visual propuesta una década antes por Los golfos (Carlos Saura, 1959) parecía casi olvidada.

Sorprendentemente la industria española, por primera vez en su historia, se benefició del desarrollo de un ciclo genérico. El cine fantástico y de terror se convirtió en el gran motor de la paupérrima industria. Esto unía al cine patrio con una corriente que se produce en Estados Unidos como es la aparición en aquel país de un cine de horror que se podría leer tanto desde el cine de género como desde un punto de vista político. Nos referimos al cine de directores como George A. Romero, Wes Craven o Tobe Hooper que en estos años comienzan sus carreras ${ }^{5}$. Desde 1968 hasta 1975 en España se rodaron más de 150 películas incluidas en ese género y supusieron casi el $20 \%$ de la producción total ${ }^{6}$. El éxito de estos largometrajes tamizó el fracaso de una industria y de un lenguaje fílmico en continua decadencia.

En este momento del tardofranquismo es cuando el cine experimental o marginal, como se le denominaba de forma mayoritaria y peyorativa entonces, se posiciona y pretende "escribir sobre ese tiempo presente y dar un orden a los gestos". Paulino Viota, Pere Portabella e Isidoro Valcárcel Medina, Premio Nacional de las Artes Plásticas 2007, filmaron en esos años tres proyectos en los que se plateaban de forma radical la intención de dar un orden a los gestos, es decir, de mostrar un nuevo código a la escritura y la interpretación cinematográficas.

Los tres directores (mejor creadores ya que el artista conceptual Valcárcel Medina siempre ha evitado ser reconocido como director de cine) entendieron que ese tiempo presente exigía una revisión completa del lenguaje cinematográfico. No se trataba de modificar un poco la estructura o estética de las películas, de narrar historias sociales o la vida de los obreros, sino que la ruptura con el franquismo debía suponer una quiebra completa con el modo de representación, con la escritura audiovisual y con el sistema de interpretación.

Las obras que analizamos Contacto (Paulino Viota, 1970), Vampir-Cuadecuc (Pere Portabella, 1970) y La celosía (Isidoro Valcárcel Medina, 1972) supusieron

\footnotetext{
4 García Fernández, E. C., Historia Ilustrada del Cine Español, Madrid, Planeta, 1984.

5 García Crego, J., «Narraciones de Horror Digital, ¿Una narración para Adolescentes?», en Espéculo. Revista de estudios literarios, Madrid, Universidad Complutense, 54 (2015), p. 10.

6 Muñoz Giner, A., Evolución del erotismo en el cine de terror español 1960-1980, Madrid, Editorial Complutense de Madrid, tesina del departamento CAVP1, 2011, p. 79.
} 
una fractura total con la tradición precedente en el cine español. El lenguaje utilizado, el método de trabajo con los intérpretes y su propuesta actoral representan uno de los cambios más radicales en el modelo. Las tres obras sitúan el conflicto de sus narraciones en la propia escritura cinematográfica. Las tres ofrecen soluciones distintas y novedosas. Estos proyectos llevan al límite el oficio de la interpretación y el propio lenguaje cinematográfico. Como indica Valente, refiriéndose al poeta Paul Celan: "El lenguaje ha descendido a las zonas infernales de la historia y ha vuelto, ha reaperecido para hablar, para ir hacia algún lugar nunca hallado"7.

Estos trabajos presentan varios aspectos en común: son películas situadas al margen de la industria y tienen metraje de mediometraje o largometraje (en este período Javier Aguirre se encontraba haciendo su "anti-cine" pero siempre en formato de cortometraje). Tanto Viota como Valcárcel Medina rodaron sin presupuesto, sin equipo profesional y sus cintas no fueron nunca estrenadas en circuitos comerciales. El caso de Pere Portabella es significativamente distinto. Su largometraje aunque igual de extravagante en muchos aspectos para la industria se transformó rápidamente en un insólito éxito en museos internacionales, universidades extranjeras y cineclubs. Hasta el punto de que Vampir-Cuadecuc fue la película española más veces proyectada en los EE.UU. ${ }^{8}$.

\section{El lenguaje aprendido: la escritura cinematográfica contra el espectador}

Régis Debray comienza uno de sus más célebres textos sobre la imagen con la siguiente descripción: "Un emperador chino pidió un día al primer pintor de su corte que borrara la cascada que había pintado al fresco en la pared del palacio porque el ruido del agua le impedía dormir. A nosotros, que creemos en el silencio de los frescos, la anécdota nos encanta. Y nos inquieta vagamente. Su lógica nos hiere, y, sin embargo, ese encanto despierta en el fondo de nosotros una sospecha adormecida: como una historia íntima más olvidada que perdida, aún amenazadora"9. El texto de Debray nos sitúa ante una de las preguntas claves que se formulan en la película Contactos: la consciencia del lenguaje de la imagen.

Este mediometraje de Paulino Viota es una de las obras capitales del cine experimental español. El film fue rodado con un presupuesto insignificante y con un equipo técnico mínimo. El director aceptó desde el inicio de la preproducción que

\footnotetext{
7 Valente, J. Á., Lectura de Paul Celan: fragmentos, Barcelona, Ediciones de la Rosa Cúbica, 1995, p. 9.

8 Gregori, A., El cine español según sus directores, Madrid, Cátedra, 2009, p. 469.

9 Debray, R., Vida y muerte de la imagen. Historia de la mirada en Occidente, Barcelona, Paidós Comunicación, 2010, p. 24.
} 
su película renunciaría a la exhibición comercial y evitaría así cualquier trámite administrativo, como indica Jaime Pena 10.

Viota y los coguionistas, Santos Zunzunegui y Javier Vega, plantearon una narración novedosa. La historia trataba sobre lo anodino y lo cotidiano. Pero los autores no buscan un argumento "débil" como diez años antes habían hecho Carlos Saura en Los golfos (1959)11 o, incluso, veinte años atrás José Antonio Nieves Conde en Surcos (1951), sino que querían narrar sobre la común y sobre lo mínimo. Su idea, en palabras del propio Viota, era mostrar de forma descarnada "la realidad rutinaria" 12 .

En Contactos lo fascinante no es lo que sucede a los protagonistas, sino la oportunidad que el director ofrece al espectador de ver los trucos de la interpretación y la escritura cinematográfica. El público es colocado ante un grupo de actores que deben representar algo imposible: lo cotidiano. Tanto Jaime Pena como Juan Manuel Company y Pablo Ferrando García al escribir sobre este largometraje han señalado la importancia del vacío. Explican cómo los tiros de cámara de los 33 planos secuencia que componen el mediometraje se han ubicado no en los lugares desde donde mejor se contempla la acción, sino desde donde se puede "revelar" mejor el vacío.

Como recalca Pena hay un intento manifiesto en cada emplazamiento por atrapar el vacío y por asimilar cinematográficamente el concepto escultórico de Jorge de Oteiza ${ }^{13}$, es decir, tensión y acción parecen reflexionar en cada plano. Por ejemplo, los encuadres de la toma de la pensión son un interesante juego de fuera de campo, los protagonistas entran y salen de la imagen. Sus acciones son insignificantes narrativamente, pero ese permanente ocultamiento a los que les somete Viota despierta el interés del público por lo que sucede, aunque estos hechos sean mínimos.

Sin embargo, el carácter más inquietante de la película lo resaltó Noël Burch: Contactos es una película de vanguardia y, al mismo tiempo, es una obra primitiva. La actuación y la interpretación de los actores no se ajustan al modelo clásico ni siquiera al modelo realista y de improvisación de las Nuevas Olas o Nouvelle Vague, sino que encaja mejor con el modo de representación primitivo ${ }^{14}$. Viota ha comentado en alguna ocasión que la actuación no fue "natural, sino que simplemen-

10 Pena, J., «Contactos», en Pérez Perucha, J. (ed.), Antología crítica del cine español 1906-1995. (pp. 677-679) Madrid: Cátedra/ Filmoteca española, 1999.

11 Deltell, L., Madrid en el cine español de los cincuenta, Madrid: Ayuntamiento de Madrid, 2006. (pp. 249-270).

12 Viota, P., «Carta sobre Contactos», en Vértigo, (1998), Coruña, edita Ateneo y Ayuntamiento de La Coruña, volumen 13/14, p.110.

13 Pena 1999. op cit. (nota 10), p. 679.

14 Burch, N., «Primitivismo y vanguardias. Un enfoque dialéctico», en Itinerarios. La educación de un soñador de cine, Bilbao, Certamen Internacional de Cine Documental, 1985. 
te no fue". La mayoría de sus intérpretes, como ocurría en el período primitivo, no eran actores profesionales ni siquiera actores aficionados 15 .

Así como un operador primitivo de la casa fundada por los hermanos Lumière, el director español decidió rodar lo cotidiano: sin elaboración en el montaje, sin iluminación y sin actuación. El propio Viota escribió:

"En Contactos debía darse la experiencia de la vivencia de la realidad, por así decir, en su totalidad, sin seleccionar nada, incorporando a los momentos filmados toda la ganga, valga la expresión, del vivir cotidiano; es decir, los tiempos muertos, los momentos más o menos inanes. Se trataba de amalgamar en un todo indisociable lo expresivo y lo inerte, plantear al hipotético espectador, provocadoramente- se puede decir que era una película planteada contra el espectador, o al menos contra sus hábitos de recepción del cine-, la imagen directa de las duraciones de la vida real, algo para lo que el cines está en principio, por su propia naturaleza, más capacitado que cualquier otro arte, pero a lo que procura renunciar para resultar más atractivo e interesante" 16 .

La actitud del director parece clara, se trata de ir contra al espectador. La interpretación de la película no pretende adentrar al espectador en la historia narrada sino alejarle de ella. Mientras que en el lenguaje clásico de Hollywood, como indica Bordwell, "la narrativa no es algo que se coloque frente al público, sino algo que se da o se cuenta" 17 . Viota lo que pretende es colocar o situar al espectador ante la vida misma y para ello presenta a una serie de actores que en realidad no son intérpretes. Se trata como expresa uno de los coguionistas de otra discusión estética: "lo que se estaba debatiendo era, nada más y nada menos, que la manera mediante la que debía darse cuenta de una conducta compleja tan específica como la del espectador-que-asiste-a-una-proyección, que el cómo definir la conciencia espectadora misma y sus relaciones con la conducta social y cultural-estética"18.

Esta vocación por colocar al espectador desprotegido frente al acontecimiento, y que además este hecho sea un suceso mínimo, hace que toda la maquinaria del lenguaje cinematográfico resulte hueca y vacía. Los actores de Contactos se presentan reales, no por encarnar perfectamente un conflicto o una trama, sino por evidenciar que no son actores. Al igual que el emperador chino en la anécdota contada por Regis Debray, el público que contempla Contactos percibe que los actores son personas reales. Como al monarca asiático, también, al espectador de la obra Viota le molesta el sonido del agua de la cascada.

\footnotetext{
15 Declaraciones de Paulino Viota en el Festival de Cine Punto de Vista de Pamplona, año 2010.

16 Viota, P., op cit., p. 110.

17 Bordwell, D.; Staiger, J.y Thompson, K., El cine clásico de Hollywood. Estilo cinematográfico y modo de producción hasta 1960, Barcelona, Paidós Comunicación, 1997, p.191.

18 Zunzunegui, S., «En el curso del tiempo», en El viejo topo, (2008), Barcelona, Ediciones de intervención cultural, numero: 242, pp. 75-76.
} 


\section{El lenguaje deconstruido: enterrar al personaje revelar al actor}

Tres años antes de que la revista de arquitectura Oppositions comenzase a discutir sobre la postmodernidad y más de una década antes de que Bernard Tschumy y Jacques Derrida planteasen el proyecto de Parc de la Villete, el poeta Joan Brossa y el cineasta Pere Portabella idearon un ejercicio de deconstrucción cinematográfico. El propio director lo sintetizó de forma certera: "(junto a Joan Brossa) habíamos hablado de la posibilidad de hacer una película sobre un guión de una película ya hecha, de una película adocenada de las que se hacían aquí (...) y sobre este tema, hacer nosotros una especie de juego"19. Vampir-Cuadecuc era la deconstrucción de otro largometraje.

La obra escogida para ser defragmentada fue Count Dracula (El conde Drácula, 1970) de Jesús Franco. Pere Portabella explicó que su proyecto consistía en acudir al rodaje y filmar lo que sucedía en el rodaje y después editar la misma historia con otro montaje. El director Jesús Franco, el productor y los actores (especialmente Christopher Lee) aceptaron. Así durante las semanas de rodaje, Portabella filmó los preparativos de los planos, las propias tomas del film Count Dracula y lo que ocurría en el escenario y los camerinos.

Vampir-Cuadecuc no es un making of sino una obra completamente distinta. En ella no se explica cómo se rodó una película sino que se cuenta de otra manera esa obra filmada. Utilizar Count Dracula para este juego fue una excelente decisión, primero por la complicidad de Jesús Franco y Christopher Lee pero, también, por el tema del largometraje y por el género. Como vimos, el cine fantástico de terror había logrado a finales de los sesenta imponerse como un estilo propio y con su universo claramente dibujado. La interpretación y la actuación de los actores eran estereotipadas y miméticas. Película tras película, las grandes estrellas de este ciclo temático repetían sus trucos, sus posturas y sus dicciones. Christopher Lee, Vicent Price o Jacinto Molina reutilizan sus actuaciones y sus mejores gestos en cada título. Lo mismo sucedía con la escritura cinematográfica, todos los guiones aunque variaban las tramas se componían de las mismas estructuras y los mismos esquemas.

La narración que nos ofrecía Jesús Franco del conde Drácula encajaba a la perfección en la represión aceptada socialmente del criminal y su condena pública. Michel Foucault presenta en su libro Vigilar y castigar el modelo: el estado incluso el pueblo "opone, en efecto, un individuo al cuerpo social entero; para castigarlo, la sociedad tiene el derecho de alzarse toda entera contra él" 20 . El gran éxito de Portabella es deconstruir y reescribir completamente este discurso y reconstruirlo en sentido contrario. En Vampir-Cuadecuc no se acepta el castigo social hacia Drácula, aunque este fuese un vampiro cruel.

19 Gregori, A., El cine español según sus directores, Madrid, Cátedra, 2009, p. 468.

20 Foucault, M., Vigilar y castigar, Madrid, Siglo XXI, 2009, p. 94. 
El mayor acierto de la obra se encuentra en la relación con los actores, en la complicidad entre Pere Portabella y los intérpretes. Así desde casi el inicio de la película tanto María Rohm como Soledad Miranda intercambian miradas y gestos con el director catalán, se dejan retratar no ya en las tomas sino incluso cuando se preparan para las mismas, cuando ensayan sus textos, cuando se maquillan y terminan jugando con la cámara de Portabella.

Aún más intenso es el trabajo de deconstrucción de Pere Portabella sobre el actor protagonista, Christopher Lee. El intérprete británico muestra más reserva ante la presencia del cineasta catalán, en los primeros momentos parece no prestarle atención pero poco a poco comienza a participar en el proyecto. Actúa para-y-con Portabella, el vampiro que el británico encarna en Vampir-Cuadecuc nada tiene que ver con el que aparece en la película de Jesús Franco. Su actuación es más sutil y más suave. La célebre estrella se deja filmar mientras le maquillan y muestra como se transforma en el temible vampiro usando unas lentillas opacas y unos dientes falsos. Lee y Portabella terminan jugando al mismo proceso deconstructivo. El director catalán afirmó: "Lee respondía a mis propósitos y se ofreció gustoso a secundarlos; incluso conseguí lo más difícil de un actor: que no hiciera nada" 21 .

Como se sabe toda Vampir-Cuadecuc se rodó muda, salvo la secuencia final, aquella en la que Christopher Lee recita a cámara el final de la novela. La escena no estaba planeada por Portabella, pero cambios en la producción de Count Dracula obligaron a modificar el proyecto del director catalán. En esta secuencia, Christopher Lee se desmaquilla, se quita todo los trucos y accesorios y se muestra tal cual es. Entonces empieza a recitar el texto, pero pronto deja de hacerlo y pide que corten y paren el motor de la cámara. El propio Lee es consciente que no ha conseguido el tono. La toma se repite y ahora el actor lee el final del libro de Bram Stoker, ya no como lo hacía antes, sino emulando el ritmo engolado de la película de Jesús Franco. La primera toma, esa que solo dura unos instantes y Lee descarta, es, en realidad, la preferida por Portabella porque es donde el actor deja de ser actor y "no hace nada".

La reescritura que nos propone Pere Portabella se basa en evidenciar los trucos y la tramoya del lenguaje del género de terror. Así se muestran las cuerdas de las que cuelgan los murciélagos, los meritorios de producción que sujetan los ventiladores que crean el humo de la escena o se exhiben la cámara, las vías y las vigas en las que descansan los focos, banderas y reflectores. La deconstrucción de esta película se basa en enseñar al espectador todos elementos técnicos y artísticos con los que se escribe una obra cinematográfica.

La última ruptura con la escritura cinematográfica se produce en el uso del negativo. Portabella propone un uso atípico del celuloide. El director catalán colo-

21 Expósito, M. (ed.), Historias sin argumento. El cine de Pere Portabella, Barcelona, Ediciones de la Mirada - Museu dÁrt Contemporani e Varcelona (MACBA), 2001, p. 279. 
ca la bobina a la inversa en la cámara, es decir, utiliza el positivo como negativo para imprimir las imágenes. De ese modo al revelar el celuloide lo que se produce es una inversión en la luz. Las partes más oscuras se transforman en las más claras y las más luminosas se oscurecen. Este recurso, provoca al espectador que mira la película con asombro y sorpresa. El texto que debería ser negro se ha convertido en blanco y las formas blancas son negras.

A pesar de Vampir-Cuadecuc se produjo en condiciones de "marginalidad" y fuera de cualquier sistema oficial, el estado franquista persiguió la película. Se intentó paralizar cualquier tipo de exhibición comercial. Sin embargo, el proyecto de Portabella logró encontrar un hueco fuera de la distribución tradicional. Como indica Josep Torrell no se trató de un éxito en salas comerciales, sino una difusión por museos, centros de arte, filmotecas y universidades. En 1972, la película se presentó en el Museum of Modern Art (MOMA) de Nueva York, Pere Portabella no pudo asistir al acto, porque el estado franquista le denegó el pasaporte por considerarlo sospechoso. En el acto se leyó una carta del director, en el que explicaba las terribles dificultades de la profesión cinematográfica, la represión sobre el movimiento obrero y la falta absoluta de libertad en España. Su texto terminaba diciendo: "Aquí está pues Vampir, no a pesar de todo, sino como resultado de todo".

\section{EI lenguaje desaparecido: sin actor}

Como se sabe, Martin Heidegger en «El origen de la obra de arte» intenta definir tres conceptos distintos y básicos: arte, artista y obra de arte. En un famoso párrafo, el filósofo germano escribe: "El artista es el origen de la obra. La obra es el origen del artista. Ninguno puede ser sin el otro. Pero ninguno de los dos soporta tampoco al otro por separado. El artista y la obra son en sí mismo y recíprocamente por medio de un tercero que viene a ser el primero, aquello de donde el artista y la obra de arte reciben su nombre: el arte"22. Isidoro Valcárcel Medina ha construido una de las propuestas estéticas más radicales, precisamente, por situarse en contra de la sentencia de Heidegger. Su planteamiento es que el artista y, sobre todo, la obra de arte no son, en esencia, relevantes en el arte.

La mayoría de las intervenciones y acciones de Isidoro Valcárcel Medina no se enmarcan en ninguna disciplina tradicional: ni cinematográficas ni pictóricas -ni siquiera encajan plenamente en el modelo de artista conceptual o performativo-. Este creador se opone radicalmente a la entronización de la obra de arte y de la figura del artista, en su percepción romántica. Todo lo contrario sus intervenciones son siempre piezas inacabadas que el espectador debe concluir y hacer suyas para que

22 Heidegger, M., Caminos en el bosque, Madrid, Alianza Universidad, 1995, p. 11. 
cobren plenitud. Rompiendo con la idea de Heidegger el creador español considera que un artista puede, y debe, ser cada ciudadano y que una obra de arte no es algo ajeno y extraordinario sino la propia vida de cada individuo: "Las gentes que hacen la vida, hacen el arte; son los mismos. Ciertos grados de especialización han conseguido esconder y eliminar, incluso, la capacidad creadora de la mayoría. Intereses de los especialistas y de sus clientes han llegado a sugestionar y someter a los espectadores. Las acciones artísticas no tienen por qué ser fundamentalmente diferentes de las cotidianas. La consciencia y la intencionalidad en éstas las convierte en estéticas" 23 .

Si la propuesta estética de Isidoro Valcárcel Medina resulta una fractura tan grande en el campo del arte experimental y de acción en el panorama español, no menos radical será su único largometraje: La celosía (1972). La obra hay que situarla dentro del contexto de los encuentros de Pamplona de 1972, evento en el cual el propio creador coincidió con Javier Aguirre que presentaba sus cortometrajes basados en su propuesta de "anti-cine"24.

La película de Valcárcel Medina se idea como una adaptación de la novela homónima de Alain Robbe-Grillet. Pero se basa en una evidencia o en una "perogrullada": cine es todo lo que se filma, aunque lo que se ruede o fotografíe sean las páginas impresas de un libro. La adaptación de Valcárcel Medina consistió en la filmación de una serie de cartones que contenían impresos el texto de la novela. El propio artista y Esther Ferrer, Premio Nacional de las Artes Plásticas 2008, leyeron los cartones con voz anodina y sin enfatizar las acciones o los sucesos que el relato describía.

Se trata, por tanto, de algo de Perogrullo, una película sobre un libro, pero no sobre el contenido de novela sino sobre el texto editado. "El placer de la obviedad, por otra parte, no deja de ser fácil y consolador; poner de manifiesto lo evidente y objetivo puede, con todo derecho, ser tildado de reiterativo -es decir, puesto a lo creativo-; sin embargo, bien estaría preguntarse por qué el autor de estas obviedades se vanagloria de haber formalizado, hace bastante tiempo el llamado Perogrullo art" 25 .

Si Viota recurre a evidenciar el lenguaje y la escritura cinematográficos, a situar al intérprete contra el espectador, y si Portabella deconstruye el oficio del intérprete, para mostrarnos los trucos de una estrella cinematográfica, Valcárcel Medina da un paso más y elimina al propio actor y la propia escritura cinematográfica. El texto de la novela de Robbe-Grillet es leído tanto por Esther Ferrer y por Valcárcel

\footnotetext{
${ }^{2}$ Cuyás Díaz, J., Ir y venir de Valcárcel Medina, Barcelona, Fundació Antoni Tàpies, 2002, p. 1.

24 Aguirre, J., Anti-cine, Madrid, Fundamentos, 1972.

25 Valcárcel Medina, I., "Sobre las paredes y el suelo", en NIEVES, Juan de (ed), Isidoro Valcárcel Medina, Vigo, Adhoc galería, 2013, p. 26.
} 
Medina sin ninguna intención, no se pretende emocionar o fascinar al espectador sino, simplemente, que suenen las frases escritas en esos cartones.

La Junta de Clasificación y Censura no objetó sobre esta obra, como recuerda Isidoro Valcárcel Medina, los censores al contemplar los primeros minutos de su película se preguntaron: “isigue así hasta el final? ¡Pues aprobada!”26. El estreno de La celosía fue escandaloso, el público incapaz de entender el juego de Perogrullo que proponía el creador salía de la sala irritado y en la taquilla del cine reclamaban el importe de la entrada de la función 27 . Sin duda, de las tres películas presentadas, la obra de Valcárcel Medina es la que se sitúa más alejada de la escritura cinematográfica, es la que lleva hasta las últimas consecuencias el uso del actor, al eliminar su imagen y mostrar su voz como algo monótona y sin intención.

\section{Conclusiones}

Más de cuarenta años después de la filmación de estas películas marginales y experimentales, el cine actual español sigue en deuda con ellas y con sus autores. Sorprende poderosamente que estas obras, especialmente dos de ellas que casi no han sido exhibidas, hayan influido tanto en el panorama reciente.

La huella del modelo de interpretación y actoral propuesto Paulino Viota en Contactos resulta evidente en las obras de Jaime Rosales, concretamente en La soledad (2007) y en Tiro en la cabeza (2008), o en el cine de Javier Rebollo, en Lo que sé de Lola (2006) y El muerto y ser feliz (2012). Las películas de Rosales y Rebollo recurren una y otra vez a encuadres y posiciones de cámara que recuerdan a las escogidas por Viota.

Vampir-Cuadecuc es de las cintas estudiadas la que ha gozado de mayor exhibición. Sin duda, esta película ha sido un éxito en universidades, centros de cine y museos. La obra de Pere Portabella es un excelente ejemplo para entender la interpretación y la tramoya del mundo del actor cinematográfico y la deconstrucción del montaje cinematográfico. Muchos de los documentales posteriores del propio director catalán reflexionarán sobre este universo de ficción y representación. Sirvan de ejemplo los juegos expuestos en Die Stille vor Bach (El silencio antes de Bach, 2007) donde los actores sólo aparecen para narrar pasajes inventados y falsos de la vida del compositor alemán.

\footnotetext{
26 La obra de Isidoro Valcárcel Medina fue estrenada en los Encuentros de Pamplona en 1972. El largometraje no pasó por la Junta de Clasificación y Censura de películas españolas, sino que "revisó" por las instituciones del evento navarro.

27 Parra Pérez, C., «Arte contra el sistema. Isidoro Valcárcel Medina», Imafronte, Murcia, Publicaciones Universidad de Murcia, Volumen 15 (2000), pp. 225-236.
} 
Pero también la actitud de Portabella de deconstrucción del mundo del cine y de los actores parece presente en la obra de otros cineastas, sobre todo, de autores recientes o jóvenes. Así se percibe su huella en el cine del colectivo Los hijos, en Elías León Siminiani, Mapa (2013) o en el reciente largometraje de Oscar Alegría, Emak Bakia (2013). Aunque donde se manifiesta más claramente su herencia es en el entorno catalán y el documental creativo surgido en el ámbito de la Universitat de Barcelona y de José Luis Guerín.

De los tres autores expuestos, el que menor influencia presenta en el cine actual es Isidoro Valcárcel Medina. La celosía ha sido exhibida en escasísimas ocasiones y no existe forma de consultarla en archivos o bibliotecas públicas, salvo las versiones conservadas en Filmoteca Española y el Museo Nacional de Centro de Arte Reina Sofía. La propuesta de este creador fue la más radical y más compleja, no admitía ninguna copia y tampoco ninguna herencia directa. Como le ocurría a la poesía de Paul Celan, resultaría casi imposible ser vástago cinematográfico de Valcárcel Medina. Sin embargo, la actitud de este artista conceptual se observa algunos de los creadores actuales: Manuel Saiz, Santiago Sierra y, sobre todo, Los torreznos, quienes han confesado en repetidas ocasiones su admiración por él28.

\footnotetext{
28 Conversación de Isidoro Valcárcel y Santiago Sierra con Jorge Díez, director de Madrid Abierto, fue proyectado en el Encuentro Madrid Abierto 2011-2012 (El Taller, Matadero Madrid, del 12 de enero al 19 de febrero).
} 